\title{
Inhibition of Fatty Acid Synthesis Induces Apoptosis of Human Pancreatic Cancer Cells
}

\author{
KOJI NISHI, KENTA SUZUKI, JUNPEI SAWAMOTO, YUMA TOKIZAWA, YUMIKO IWASE, \\ NAGAHIKO YUMITA and TOSHIHIKO IKEDA \\ Laboratory of Drug Metabolism and Pharmacotherapeutics, \\ Department of Clinical Pharmacy, Yokohama University of Pharmacy, Yokohama, Japan
}

\begin{abstract}
Cancer cells tend to have a high requirement for lipids, including fatty acids, cholesterol and triglyceride, because of their rapid proliferative rate compared to normal cells. In this study, we investigated the effects of inhibition of lipid synthesis on the proliferation and viability of human pancreatic cancer cells. Of the inhibitors of lipid synthesis that were tested, 5-(tetradecyloxy)-2-furoic acid (TOFA), which is an inhibitor of acetyl-CoA carboxylase, and the fatty acid synthase (FAS) inhibitors cerulenin and irgasan, significantly suppressed the proliferation of MiaPaCa-2 and AsPC-1 cells. Treatment of MiaPaCa-2 cells with these inhibitors significantly increased the number of apoptotic cells. In addition, TOFA increased caspase-3 activity and induced cleavage of poly (ADP-ribose) polymerase in MiaPaCa-2 cells. Moreover, addition of palmitate to MiaPaCa-2 cells treated with TOFA rescued cells from apoptotic cell death. These results suggest that TOFA induces apoptosis via depletion of fatty acids and that, among the various aspects of lipid metabolism, inhibition of fatty acid synthesis may be a notable target for the treatment of human pancreatic cancer cells.
\end{abstract}

Pancreatic cancer is one of the most lethal of human cancers; it is the fourth leading cause of cancer-related death in the United States and the fifth leading cause in Japan. Although standard chemotherapy regimens consisting of oxaliplatin, irinotecan, fluorouracil, and leucovorin (FOLFIRINOX) or gemcitabine and nab-paclitaxel are wildly used to treat patients with advanced pancreatic cancer, their antitumor effects (progression and survival rates) in pancreatic cancer are less well known than their effects on other solid tumors $(1,2)$.

Correspondence to: Koji Nishi, Laboratory of Drug Metabolism and Pharmacotherapeutics, Department of Clinical Pharmacy, Yokohama University of Pharmacy, 601 Matano-cho, Totsuka-ku, Yokohama, Kanagawa 245-0066, Japan. Tel: +81 458591300, Fax: +81 458591301, e-mail: k.nishi@hamayaku.ac.jp

Key Words: apoptosis, fatty acid synthesis, pancreatic cancer, TOFA
Tumors are generally known to need more lipids as energy sources compared to normal cells. Indeed, several lipogenic enzymes in various tumors contribute to the production of a large number of lipids for the survival and proliferation of cancer cells (3). Acetyl-CoA carboxylase (ACC), which catalyzes the carboxylation of acetyl-CoA to malonyl-CoA, is the rate-limiting enzyme for the synthesis of fatty acids (4). Inhibition of ACC was reported to inhibit the growth and apoptosis of prostate, ovarian, breast, lung and colon cancer cells (5-8). Fatty acid synthase (FAS) is involved in the elongation of fatty acids during their biosynthesis. Overexpression of FAS has been detected in cancer cells and was reported to predict a poor prognosis for human gastric, breast and ovarian cancer (9-15). Murata et al. found that Inhibition of FAS suppressed the proliferation of colon cancer cells in mice, which was followed by the induction of apoptosis (16). Moreover, several groups have suggested that agonists of peroxisome proliferator-activated receptor (PPAR) $\alpha$, PPAR $\gamma$ and hydroxymethylglutaryl-CoA (HMG-CoA) reductase exerted an antitumor effect by reducing the levels of triacylglycerol and cholesterol (17-21). However, which aspect of lipid metabolism might be the best target for inhibition in order to provide the most effective induction of pancreatic cancer cell death is unclear. We, therefore, hypothesized that such an understanding would be useful in the development of a therapeutic strategy.

In the current study, in order to test the above hypothesis, we examined the effect of different lipid metabolism inhibitors on the proliferation of pancreatic cancer cells. We also discuss the possibility of using ACC inhibition as a new therapeutic target for pancreatic cancer cells.

\section{Materials and Methods}

Cell cultures and reagents. The human pancreatic cancer cell lines, MiaPaCa-2 and AsPC-1 were obtained from the American Type Culture Collection (Manassas, VA, USA). The cells were cultured in recommended Dulbecco's Modified Eagle Medium (DMEM) or RPMI1640 medium, supplemented with $10 \%$ heat-inactivated fetal calf serum (GIBCO, Invitrogen, Carlsbad, CA, USA), penicillin 
$100 \mathrm{U} / \mathrm{ml}$ and streptomycin $100 \mathrm{pg} / \mathrm{ml}$ (Sigma-Aldrich, St. Luis, MO, USA) in $95 \%$ humidified air and $5 \%$ carbon dioxide at $37^{\circ} \mathrm{C}$. 5(tetradecyloxy)-2-furoic acid (TOFA) (ACC inhibitor), irgasan (FAS inhibitor), cerulenin (FAS inhibitor), simvastatin (HMG-CoA reductase inhibitor), pravastatin (HMG-CoA reductase inhibitor), bezafibrate (PPAR $\alpha$ agonist), fenofibrate (PPAR $\alpha$ agonist), rosiglitazone (PPAR $\gamma$ agonist) and palmitate were purchased from Sigma-Aldrich. Troglitazone (PPAR $\gamma$ agonist) was a gift from Daiichi Sankyo Co., Ltd (Japan).

MTS assay. Cell viability was evaluated using MTS solution (Promega Corp., Madison, WI, USA). Cancer cells were seeded at a density of 3,000 cells/well in 96-well flat-bottom plates. After incubation overnight, the cells were continuously exposed to different concentrations $(0-100 \mu \mathrm{M})$ of inhibitors for 24,48 and $72 \mathrm{~h}$. Subsequently, after $2 \mathrm{~h}$ incubation with MTS reagent at $37^{\circ} \mathrm{C}$, the absorbance was measured at $490 \mathrm{~nm}$ in a microplate reader (Biorad, Hercules, CA, USA). All experiments were repeated three times.

Annexin $V$ and dead cell assay. Live and apoptotic cell numbers were determined using MUSE Annexin V and Dead Cell kit (Merck Millipore KGaA, Darmstadt, Germany) according to the manufacturer's instructions. Briefly, cells were seeded at a density of $2.0 \times 10^{5}$ cells/well in six-well plates. After $12 \mathrm{~h}$, inhibitors were added to each well and incubated for $24 \mathrm{~h}$. The cells were then washed twice with phosphate buffered saline, were trypsinized and were mixed well with the Muse Annexin V and Dead Cell Assay kit reagents (Merck Millipore). Assays were analyzed using a MUSE Cell Analyzer and were conducted in triplicate.

Caspase-3 activity assay. Cellular caspase-3 activity was measured using Caspase-3/CRP32 Fluorometric Assay Kit (Biovision, Mountain View, CA, USA). Briefly, cells were seeded at a density of $2 \times 10^{5}$ cells/well in six-well plates. After incubation with TOFA for $24 \mathrm{~h}$, the cells were trypsinized, mixed with Cell Lysis Buffer and incubated on ice for $10 \mathrm{~min}$. The Asp-Glu-Val-Asp-7-amino-4-trifluoromethyl coumarin (DEVD-AFC) substrate was then added to the lysed cell solution and incubated for $2 \mathrm{~h}$. The fluorescent intensity (FI) of samples was measured at $400 \mathrm{~nm}$ excitation and $505 \mathrm{~nm}$ emission and data were analyzed as FI relative to that of controls. Assays were conducted in triplicate.

Western blot analysis. Cells were seeded at a density of $5.0 \times 10^{5}$ cells/well in six-well plates. After $12 \mathrm{~h}$, TOFA was added to each well and plate were further incubated for $24 \mathrm{~h}$. The cells were washed twice with PBS, and were then lysed with RIPA buffer (Thermo Fisher Scientific, San Jose, CA, USA), including a Protease/Phosphatase Inhibitor Cocktail (Cell Signaling Technology, Beverly, MA, USA). Aliquots of protein $(30-40 \mu \mathrm{g})$ were subjected to polyacrylamide gel electrophoresis $(12 \%)$, transferred to a polyvinylidene difluoride membrane, and processed for incubation with primary antibodies for $1 \mathrm{~h}$, followed by secondary antibodies for $1 \mathrm{~h}$. Membranes were reacted with a chemiluminescence reagent (GE Healthcare, Piscataway, NJ, USA). Band density values were normalized to glyceraldehyde-3-phosphate dehydrogenase (GAPDH). Primary antibodies used were specific to poly (ADP-ribose) polymerase (PARP) and GAPDH (Abcam, Austin, TX, USA). AntiPARP antibody and anti-GAPDH antibody were used at $\times 1,000$ and $\times 10,000$ dilution respectively.

Palmitate rescue assay. This assay was performed according to the method of Chun et al. (8). Briefly, four volumes of $4 \%$ fatty acid-free bovine serum albumin (BSA) in $0.9 \% \mathrm{NaCl}$ were mixed with 1 volume of $5 \mathrm{mM}$ palmitate (Sigma-Aldrich) in ethanol and incubated at $37^{\circ} \mathrm{C}$ for $2 \mathrm{~h}$ to form a $1 \mathrm{mM}$ palmitate-BSA complex. This complex was added to each well at a concentration of $1 \mu \mathrm{M}$ with TOFA. After incubation for $24 \mathrm{~h}$, the cells were then washed twice with PBS, were trypsinized and were mixed well with the Muse Annexin V and Dead Cell Assay kit reagents (Merck Millipore). Assays were analyzed using a MUSE Cell Analyzer and were conducted in triplicate.

Statistical analysis. The overall differences between groups were determined by one-way of analysis of variance (ANOVA).

\section{Results}

Inhibitor-induced suppression of cell proliferation. To investigate which lipid metabolism pathways are important for the proliferation of human pancreatic cancer cells, the effects of inhibitors of ACC, FAS and HMG-CoA reductase, and of PPAR $\alpha$ and $-\gamma$ agonists, on the viability of MiaPaCa- 2 and AsPC-1 cells were examined (Figure 1A and B, respectively). Among the inhibitors of fatty acid synthesis, TOFA suppression of the growth of MiaPaCa-2 and AsPC-1 cells was stronger than that of cerulenin and irgasan. Both troglitazone and rosiglitazone suppressed cell growth at concentrations higher than $10 \mu \mathrm{M}$, although the degree of suppression was higher for troglitazone. Although simvastatin suppressed the growth of MiaPaCa-2 and AsPC-1 cells, pravastatin had little effect. The results shown in Figure 1 indicate that inhibitors of fatty acid synthesis, TOFA, cerulenin and irgasan, suppressed the growth of $\mathrm{MiaPaCa}-2$ and AsPC-1 cells to a greater extent than PPAR $\alpha$ and PPAR $\gamma$ agonists, and inhibitors of HMG-CoA reductase.

Induction of apoptosis by TOFA. To further investigate the effect of TOFA, we determined whether treatment with TOFA for 24 $\mathrm{h}$ induces apoptosis in MiaPaCa-2 cells. TOFA indeed induced significant apoptosis (Figure 2A) and increased the number of total and late apoptotic cells and reduced early apoptotic cells in a concentration-dependent manner (Figure 2B).

Caspase- 3 is known to be activated during apoptosis, when it catalyzes the specific cleavage of many cellular factors. We therefore investigated caspase- 3 activity in $\mathrm{MiaPaCa}-2$ cells after treatment with TOFA (Figure 2C). TOFA significantly increased caspase- 3 activity by more than two-fold compared to control at TOFA concentrations of between 20 and $80 \mu \mathrm{M}$.

PARP is cleaved by activated caspase- 3 during early apoptosis. To confirm apoptosis induction by TOFA, we examined whether TOFA causes the cleavage of PARP. As shown in Figure 2D, cleaved PARP was indeed generated by TOFA treatment of MiaPaCa- 2 cells. The highest intensity of the cleaved PARP band on the western blot was observed at the lowest concentration of TOFA used $(20 \mu \mathrm{M})$. 

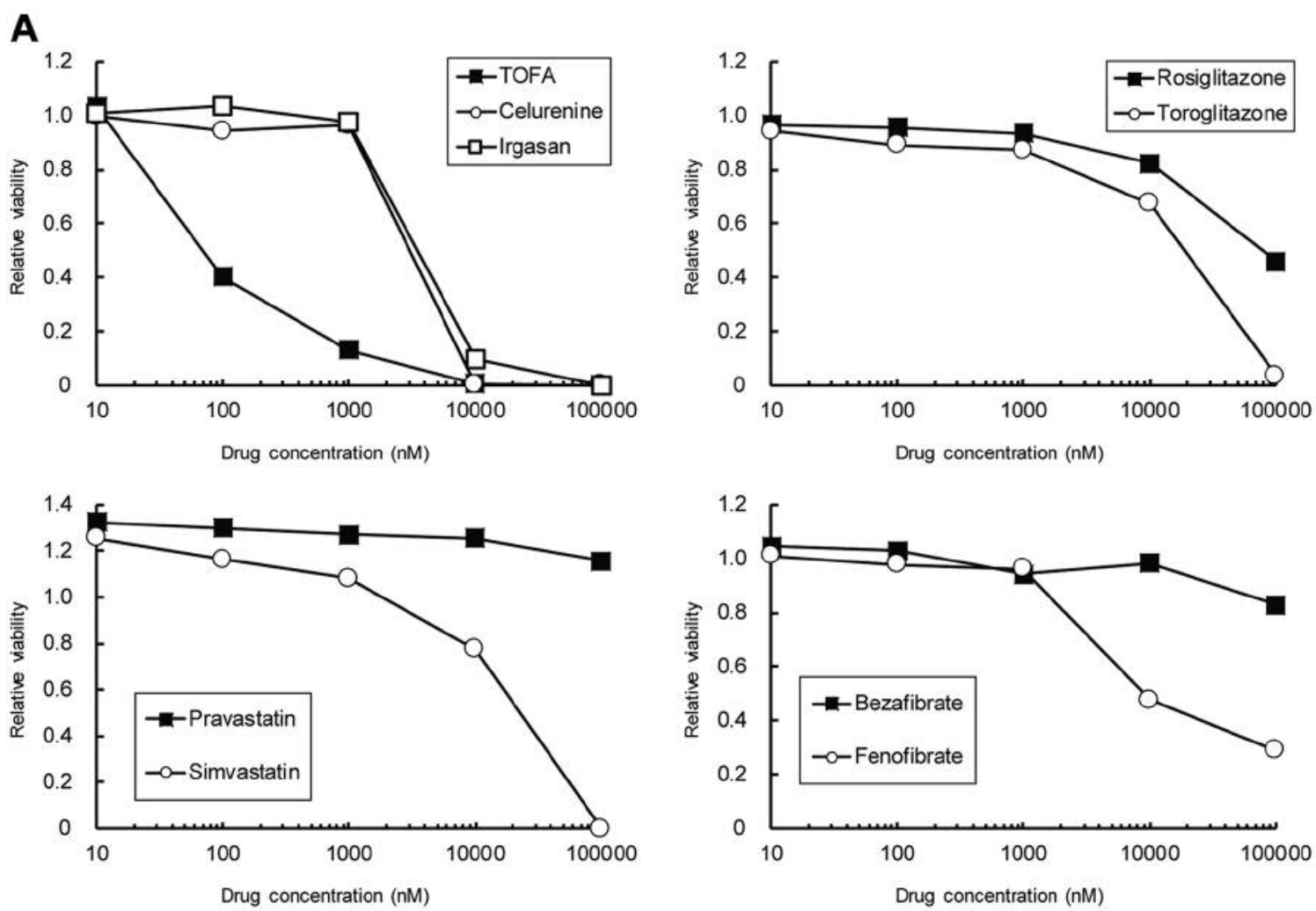

B
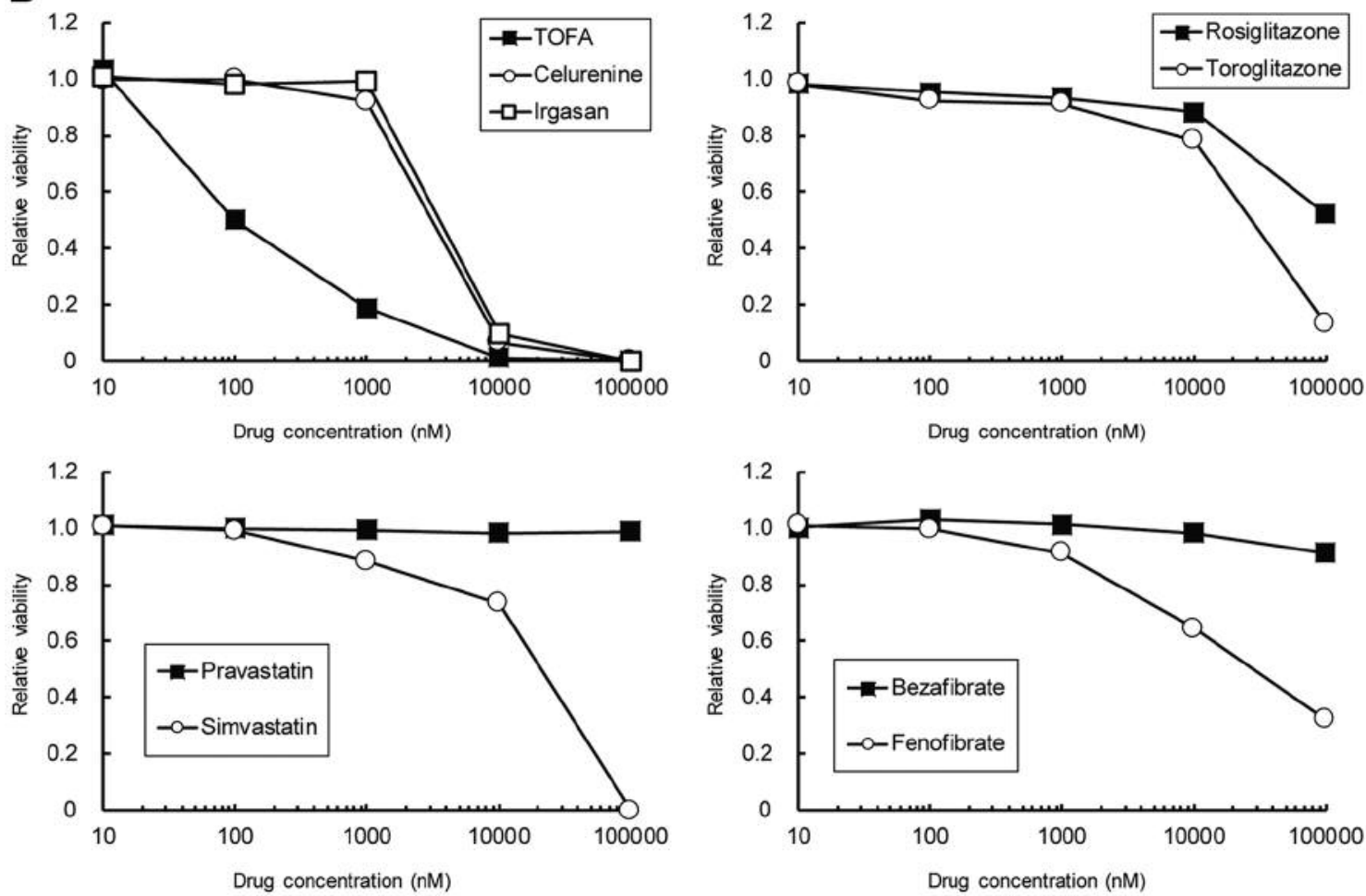

Figure 1. Growth inhibition of MiaPaCa-2 (A) and AsPC-1 (B) cells by inhibitors of different lipid synthesis pathways. The cells were treated with increasing concentrations of 5-(tetradecyloxy)-2-furoic acid (TOFA), cerulenin, irgasan, rosiglitazone, troglitazone, pravastatin, simvastatin, bezafibrate and fenofibrate (1-100 $\mu \mathrm{M})$. After $72 \mathrm{~h}$, viable cells were quantified using the MTS reagent. Each data point indicates the mean of three independent experiments. 
A Control

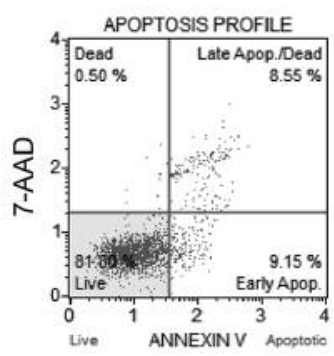

$60 \mu \mathrm{M}$

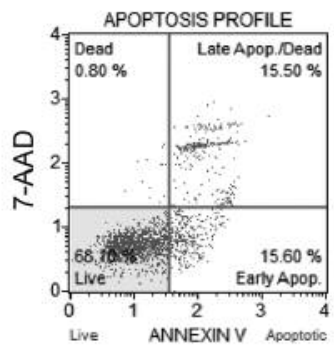

$20 \mu \mathrm{M}$

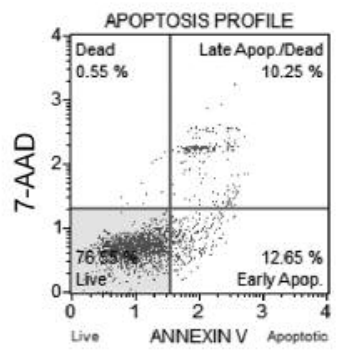

$80 \mu \mathrm{M}$

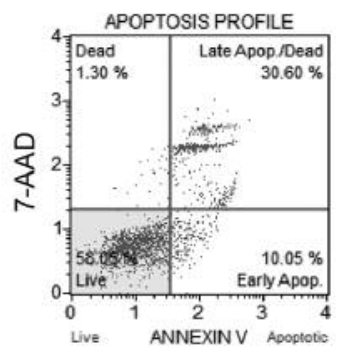

$40 \mu \mathrm{M}$

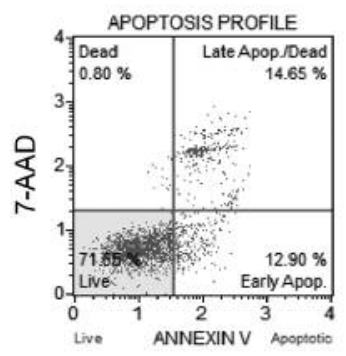

B

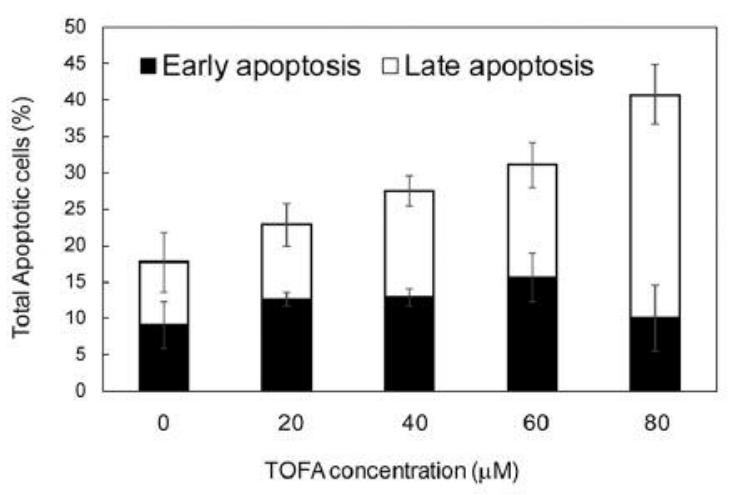

C

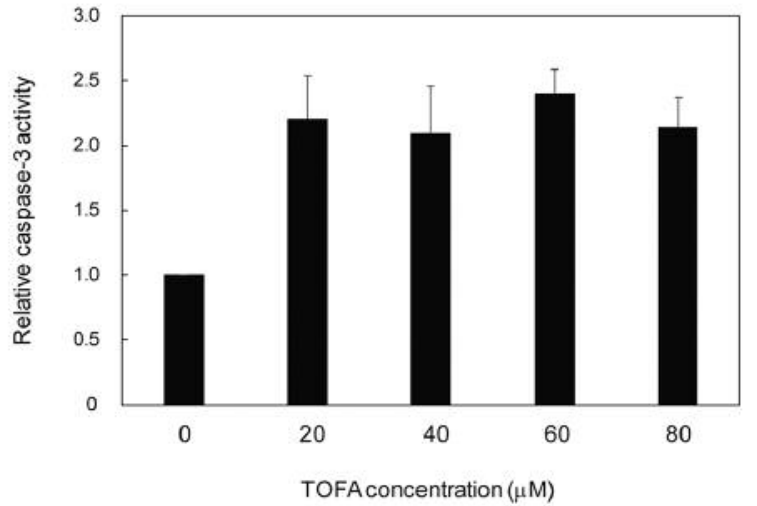

TOFA $(\mu \mathrm{M})$

D $\begin{array}{lllll}0 & 20 & 40 & 60 & 80\end{array}$

Cleaved PARP

GAPDH

Figure 2. Induction of apoptosis of MiaPaCa-2 cells by 5-(tetradecyloxy)-2-furoic acid (TOFA). The cells were treated with increasing concentrations of TOFA $(20,40,60$ and $80 \mu \mathrm{M})$. After $24 \mathrm{~h}$, viable, apoptotic and dead cells were quantified using a MUSE cell analyzer. A: The assay distinguishes live cells (annexin $V$ - and 7-amino-actinomycin $(7-A A D)^{-}$; lower left quadrant), early apoptotic cells (annexin $V^{+}$and 7-AAD ${ }^{-}$; lower right quadrant), late apoptotic and dead cells (annexin $V^{+}$and $7-A A D^{+}$; upper right quadrant), and cells that have lost their phosphatidylserine or dead cells (annexin $V^{-}$and 7-AAD+; upper left quadrant). B: The percentage of early and late apoptotic cells at different TOFA concentrations. Each bar indicates the mean $\pm S D$ from three independent measurements. C: Caspase-3 activity in TOFA-treated MiaPaCa-2 cells. Caspase-3 activity was measured as the fluorescence intensity of the degradation product of the caspase-3 substrate, Asp-Glu-Val-Asp-7-amino-4-trifluoromethyl coumarin. Each bar indicates the mean $\pm S D$ from three independent measurements. D: Western blot of the effect of TOFA treatment on poly (ADP-ribose) polymerase (PARP) cleavage. MiaPaCa-2 cells were treated with the indicated amounts of TOFA and cell lysates were then analyzed by western blotting to detect the level of cleaved $P A R P$, as described in Materials and Methods. Glyceraldehyde-3-phosphate dehydrogenase (GAPDH) was probed to indicate the relative amounts of loaded proteins. 


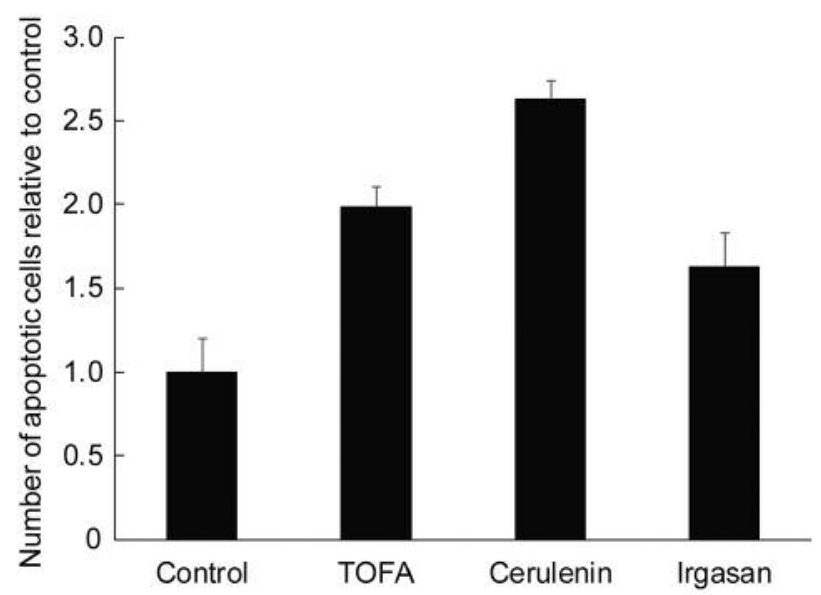

Figure 3. Induction of apoptosis of MiaPaCa-2 cells by 5-(tetradecyloxy)2-furoic acid (TOFA), cerulenin and irgasan. The cells were treated with TOFA, cerulenin and irgasan at a concentration of $40 \mu \mathrm{M}$ respectively. After $24 \mathrm{~h}$, viable, apoptotic and dead cells were quantified using a MUSE cell analyzer. Each bar indicates the mean $\pm S D$ from three independent measurements.

Effect of fatty acid depletion on induction of apoptosis by TOFA. To investigate whether apoptosis induction by TOFA is due to inhibition of fatty acid synthesis, the effect of other fatty acid synthesis inhibitors was examined. Cerulenin and irgasan were also found to induce apoptosis in MiaPaCa-2 cells, even though the degree of apoptosis induced by irgasan was lower than that of TOFA and cerulenin (Figure 3). To confirm that fatty acid depletion by TOFA induces apoptosis, the effect of supplementation of the cells with palmitate on cell death was investigated. Addition of palmitate significantly blocked the induction of apoptosis by TOFA (Figure 4).

\section{Discussion}

In this study, we found that out of the inhibitors of fatty acid metabolism that were tested, TOFA exhibited the strongest growth suppression of human pancreatic cancer cells. Simvastatin, an HMG-CoA reductase inhibitor, inhibited cellular growth at high concentrations. It was previously reported that an accumulation of lipid droplets in pancreatic cancer cells as a result of treatment with simvastatin induce the suppression of proliferation (22). In addition, Borahay et al. reported that simvastatin induced calcium-dependent apoptosis in human leiomyoma cells (23). Conversely, we found that pravastatin did not significantly suppress cell growth. A similar experimental result was also reported by the group of Gbelcova et al. (24). The difference between the effect of simvastatin and pravastatin may be due to a difference in their uptake into cells, since simvastatin is more

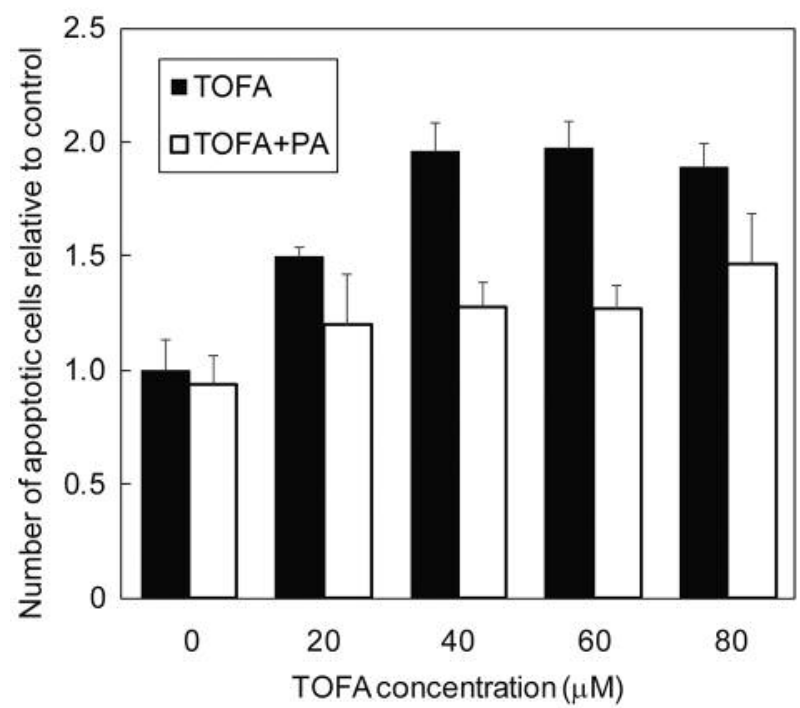

Figure 4. Palmitate (PA) rescue of MiaPaCa-2 cells from 5-(tetradecyloxy)2-furoic acid (TOFA)-induced apoptosis. The cells were treated with increasing concentrations of TOFA $(0,20,40,60$ and $80 \mu \mathrm{M})$ with or without PA $(1 \mu \mathrm{M})$. After $24 \mathrm{~h}$, the total number of apoptotic cells was quantified using a MUSE cell analyzer. Each bar indicates the mean $\pm S D$ from three independent measurements.

hydrophobic than pravastatin (LogP: simvastatin, 4.7: pravastatin, 2.2). However, a difference in hydrophobicity cannot fully explain the difference between the effects of fenofibrate and bezafibrate on cell growth ( LogP: fenofibrate, 4.9: bezafibrate, 4.0). Therefore, other factors may be involved in their different effects.

We found that TOFA induced apoptosis in MiaPaCa-2 cells by using an annexin $\mathrm{V}$ and dead cell assay, caspase- 3 activity assay and observation of PARP cleavage. The decrease in the amount of cleaved PARP that occurred in a TOFA concentration-dependent manner indicated that higher concentrations of TOFA induced more late apoptosis of MiaPaCa-2 cells. Indeed, TOFA increased the late apoptotic fraction in a concentration-dependent manner (Figure 2A). Moreover, the findings that cerulenin and irgasan also induced apoptosis of MiaPaCa- 2 cells, and that palmitate rescued the cells from apoptosis induction by TOFA, suggests that depletion of fatty acids is fatal for pancreatic cancer cells.

The fact that cancer cells have a high potential for proliferation and survival even in a nutrient starvation state may be based on a high potential for cellular fatty acid synthesis. The high expression of ACC and FAS that is found in the tumors of patients with pancreatic cancer contributes to the synthesis of high amounts of fatty acids and high cell viability under nutrient starvation. The findings of the current study suggest that inhibition of ACC could be a therapeutic target of pancreatic cancer. 


\section{Acknowledgements}

This work was supported, in part, by a Grant-in-Aid for Young Scientists (B) from the Japan Society for the Promotion of Science to Koji Nishi (No. 26860115).

\section{References}

1 Conroy T, Desseigne F, Ychou M, Bouché O, Guimbaud R, Bécouarn Y, Adenis A, Raoul JL, Gourgou-Bourgade S, de la Fouchardière C, Bennouna J, Bachet JB, Khemissa-Akouz F, Péré-Vergé D, Delbaldo C, Assenat E, Chauffert B, Michel P, Montoto-Grillot C, Ducreux M; Groupe Tumeurs Digestives of Unicancer; PRODIGE Intergroup: FOLFIRINOX versus gemcitabine for metastatic pancreatic cancer. N Engl J Med 364: 1817-1825, 2011.

2 Von Hoff DD, Ervin T, Arena FP, Chiorean EG, Infante J, Moore M, Seay T, Tjulandin SA, Ma WW, Saleh MN, Harris M, Reni M, Dowden S, Laheru D, Bahary N, Ramanathan RK, Tabernero J, Hidalgo M, Goldstein D, Van Cutsem E, Wei X, Iglesias J and Renschler MF: Increased survival in pancreatic cancer with nabpaclitaxel plus gemcitabine. N Engl J Med 369: 1691-1703, 2013.

3 Menendez JA, Colomer R, Lupu R: Why does tumor-associated fatty acid synthase (oncogenic antigen-519) ignore dietary fatty acids? Med Hypotheses 64: 342-349, 2005.

4 Kim KS, Lee JK and Kim KH: Differential use of acetyl-CoA carboxylase genes in the control of diverse cellular processes. Biochem Soc Trans 25: 1211-1215, 1997.

5 Brusselmans K, De Schrijver E, Verhoeven G and Swinnen JV: RNA interference-mediated silencing of the acetyl-CoAcarboxylase-alpha gene induces growth inhibition and apoptosis of prostate cancer cells. Cancer Res 65: 6719-6725, 2005.

6 Li S, Qiu L, Wu B, Shen H, Zhu J, Zhou L, Gu L and Di W: TOFA suppresses ovarian cancer cell growth in vitro and in vivo. Mol Med Rep 8: 373-378, 2013.

7 Chajès V, Cambot M, Moreau K, Lenoir GM, Joulin V: AcetylCoA carboxylase alpha is essential to breast cancer cell survival. Cancer Res 66: 5287-5294, 2006.

8 Wang C, Xu C, Sun M, Luo D, Liao DF and Cao D: Acetyl-CoA carboxylase-alpha inhibitor TOFA induces human cancer cell apoptosis. Biochem Biophys Res Commun 385: 302-306, 2009.

9 Gansler TS, Hardman W 3rd, Hunt DA, Schaffel S and Hennigar RA: Increased expression of fatty acid synthase (OA-519) in ovarian neoplasms predicts shorter survival. Hum Pathol 28: 686692, 1997.

10 Xiang HG, Hao J, Zhang WJ, Lu WJ, Dong P, Liu YB and Chen L: Expression of fatty acid synthase negatively correlates with PTEN and predicts peritoneal dissemination of human gastric cancer. Asian Pac J Cancer Prev 16: 6851-6855, 2015.

11 Milgraum LZ, Witters LA, Pasternack GR and Kuhajda FP: Enzymes of the fatty acid synthesis pathway are highly expressed in in situ breast carcinoma. Clin Cancer Res 3: 2115-2120, 1997.

12 Alò PL, Visca P, Trombetta G, Mangoni A, Lenti L, Monaco S, Botti C, Serpieri DE and Di Tondo: Fatty acid synthase (FAS) predictive strength in poorly differentiated early breast carcinomas. Tumori 85: 35-40, 1999.

13 Nakamura I, Kimijima I, Zhang GJ, Onogi H, Endo Y, Suzuki S, Tuchiya A, Takenoshita S, Kusakabe T and Suzuki T: Fatty acid synthase expression in Japanese breast carcinoma patients. Int J Mol Med 4: 381-387, 1999.
14 Swinnen JV, Vanderhoydonc F, Elgamal AA, Eelen M, Vercaeren I, Joniau S, Van Poppel H, Baert L, Goossens K, Heyns W and Verhoeven G: Selective activation of the fatty acid synthesis pathway in human prostate cancer. Int J Cancer 88: 176-179, 2000.

15 Swinnen JV, Roskams T, Joniau S, Van Poppel H, Oyen R, Baert L, Heyns W and Verhoeven G: Overexpression of fatty acid synthase is an early and common event in the development of prostate cancer. Int J Cancer 98: 19-22, 2002.

16 Murata S, Yanagisawa K, Fukunaga K, Oda T, Kobayashi A, Sasaki R and Ohkohchi N: Fatty acid synthase inhibitor cerulenin suppresses liver metastasis of colon cancer in mice. Cancer Sci 101: 1861-1865, 2010.

17 Tsubouchi Y, Sano H, Kawahito Y, Mukai S, Yamada R, Kohno M, Inoue K, Hla T and Kondo M: Inhibition of human lung cancer cell growth by the peroxisome proliferator-activated receptorgamma agonists through induction of apoptosis. Biochem Biophys Res Commun 270: 400-405, 2000.

18 Koyama M, Sowa Y, Horinaka M, Goda AE, Fujiwara J and Sakai T: Peroxisome proliferator-activated receptor $\gamma$ ligand troglitazone and TRAIL synergistically induce apoptosis. Oncol Rep 31: 947954, 2014.

19 Yan S, Yang X, Chen T, Xi Z and Jiang X: The PPAR $\gamma$ agonist Troglitazone induces autophagy, apoptosis and necroptosis in bladder cancer cells. Cancer Gene Ther 21: 188-193, 2014.

20 Jang HJ, Hong EM, Park SW, Byun HW, Koh DH, Choi MH, Kae SH and Lee J: Statin induces apoptosis of human colon cancer cells and down-regulation of insulin-like growth factor 1 receptor via proapoptotic ERK activation. Oncol Lett 12: 250-256, 2016.

21 Wang T, Seah S, Loh X, Chan CW, Hartman M, Goh BC and Lee SC: Simvastatin-induced breast cancer cell death and deactivation of PI3K/AKT and MAPK/ERK signalling are reversed by metabolic products of the mevalonate pathway. Oncotarget 7: 2532-2544, 2016.

22 Gbelcová H, Svéda M, Laubertová L, Varga I, Vítek L, Kolář M, Strnad H, Zelenka J, Böhmer D and Ruml T: The effect of simvastatin on lipid droplets accumulation in human embryonic kidney cells and pancreatic cancer cells. Lipids Health Dis 12: 126, 2013.

23 Borahay MA, Kilic GS, Yallampalli C, Snyder RR, Hankins GD, Al-Hendy A and Boehning D: Simvastatin potently induces calcium-dependent apoptosis of human leiomyoma cells. J Biol Chem 289: 35075-35086, 2014.

24 Gbelcová H, Lenícek M, Zelenka J, Knejzlík Z, Dvoráková G, Zadinová M, Poucková P, Kudla M, Balaz P, Ruml T and Vítek L: Differences in antitumor effects of various statins on human pancreatic cancer. Int J Cancer 122: 1214-1221, 2008. 